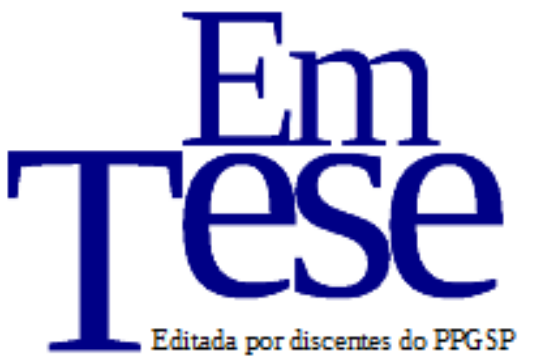

UFSC

PPG SP PROG RAMA DE

PÓS-GRADUAÇÃO EM

Sociologia

Política

v. 14, n. 1, jan./jun., 2017

\title{
O discurso do "pioneiro colonizador" como elitismo cultural na cidade de Toledo/PR
}

\author{
Carlos Eduardo Bao ${ }^{1}$
}

\begin{abstract}
Resumo: É lugar comum na sociologia estudos acerca de relações de poder e dominação. Numa perspectiva relacional, é possível identificar esse tipo de relação imbricada nas várias esferas da vida social, configurando lutas acirradas pelo domínio no campo do poder seja ele econômico, político ou cultural. As pesquisas sobre elitismo, orientadas nesse sentido, vem estabelecendo prolíficos estudos sobre os grupos dirigentes, seus espaços específicos de dominação e suas intersecções. Proponho aqui pensarmos o discurso do "pioneiro colonizador" como um mecanismo de dominação cultural, ligado a aspectos eminentemente simbólicos. Para isso, analiso o caso da "elite pioneira" dominante na cidade de Toledo, Paraná, onde a história da "colonização" serve (ou pretende servir) como um ethos na constituição dos modelos de representações para a população local em geral.
\end{abstract}

Palavras-chave: Pioneirismo. Elitismo. Ethos. Capital simbólico. Toledo/PR.

\begin{abstract}
It is commonplace in sociology studies on relations of power and domination. In a relational perspective, you can identify this type of imbricated relationship in various spheres of social life, setting up fights fierce for dominance in the field of power. Research on elitism, oriented in this direction, has established prolific studies of the ruling groups, their specific areas of domination and their intersections. I propose here think the discourse of "colonizing pioneer" as a mechanism of domination on the highly symbolic and cultural aspects. For this, I analyze the case of the "pioneer elite" ruling in the city of Toledo, Paraná, where the history of the "colonization" is used (or intend to serve) as an ethos in the constitution of representations of models for the local population in general.
\end{abstract}

Keywords: Pioneering; elitism; ethos; symbolic capital; Toledo/PR.

\footnotetext{
${ }^{1}$ Doutorando em Sociologia Política, PPGSP/UFSC. E-mail: carloseduardobao@ hotmail.com.
} 
O objetivo do texto consiste em demonstrar a faceta elitista do discurso do chamado "pioneiro colonizador" na cidade de Toledo, região oeste do Paraná, elaborando seu aspecto simbólico, sociologicamente, como uma relação social de dominação, onde a representação do pioneirismo cria padrões de normatividade e precedência histórico-civilizacional no local marcos temporais.

O estudo do elitismo remete a uma problemática tradicionalmente abordada pela ciência política. Conforme Seidl (2013) duas interpretações predominaram nas discussões provenientes da escola inglesa e estadunidense: o elitismo versus o pluralismo; voltadas, respectivamente, para as relações e laços sociais dos agentes da elite ou então para os mecanismos institucionais de decisão. Na sociologia há debates em torno de concepções mais substancialistas de poder, como é o caso dos chamados funcionalismo e marxismo em contraste com perspectivas mais relacionais, como em Bourdieu (1989), Giddens (2003) e, mais acentuadamente, na corrente dita pós-estruturalista.

Ainda segundo Seidl (2012), os estudos sobre as elites adquirem novo fôlego com a contribuição do sociólogo Pierre Bourdieu (1930-2002), a partir da penúltima década do século passado. O principal ponto de ruptura da sociologia do poder de Bourdieu consiste em conceber o espaço social como formado por esferas com lógicas específicas. Esses campos, porém, seriam interdependentes, gozando de autonomia e heteronomia relativas uns aos outros, dependendo do tempo e do espaço no qual se inscrevem. Além disso, em Bourdieu o poder se manifesta igualmente em termos simbólicos, onde conceitos como capital cultural e capital simbólico são chaves para se compreender e explicar os investimentos de agentes em determinadas práticas sociais não fundamentalmente utilitaristas (BOURDIEU, 1996b; 2008).

Segue-se que, tal como os espaços sociais, os poderes, as formas e os mecanismos de dominação são múltiplos. Numa tal perspectiva não se fala em grupo dirigente, mas em grupos, isto é, em elites, dependendo de que esfera social, de que campo mais especificamente, estamos falando - aqui também justifica-se a necessidade da praxiologia. ${ }^{2}$ Nesse sentido, "o que se tem são diversos grupos de agentes sociais que ocupam posições dominantes em uma ou mais esferas do mundo social, como as elites políticas, jurídicas, religiosas, econômicas, culturais, burocráticas" (SEIDL, 2013, p. 183). Como fica demonstrado ao longo do texto, a dominação da elite pioneira, em Toledo, apresenta uma faceta cultural visível tanto no espaço urbano como em determinadas obras da literatura e historiografia local, onde a narrativa do pioneirismo, tal como apresentada pelos autodenominados pioneiros, assume o lugar central de referência cultural para a construção da história local.

\footnotetext{
${ }^{2} 4$ Cf. "Introdução a uma sociologia reflexiva”, Bourdieu (1989, p. 17-58).
} 
Doravante, aproprio-me de aspectos relativos à perspectiva bourdieusiana de estudo do poder para delinear uma espécie de elitismo proporcionado por um discurso muito presente em regiões de imigração e posterior modernização, como é o caso da região Sul do Brasil - Rio Grande do Sul, Santa Catarina, Paraná. É o discurso do "colonizador pioneiro". São assim considerados, em suma, os imigrantes "teutos" e "ítalos" que povoaram vastas áreas de terras ditas devolutas nas três unidades federativas do sul, numa empreitada marcadamente racionalista promovida a partir de meados do século 19 e estendendo-se, com intensidades variadas, durante aproximadamente cem anos.

Quanto ao discurso do pioneirismo, especificamente, parece ser mais atual. Manifestado por alguns contingentes desses "colonizadores pioneiros" e também por seus descendentes que reivindicam no presente a prioridade histórica - e, com isso, simbólica e cultural - em determinadas cidades e regiões do Sul a seus antepassados. Além de estabelecer uma temporalidade específica sobre determinados espaços - e hierarquias entre os grupos que o constituem -, tal discurso invisibiliza, na narrativa histórica e no espaço social, outros grupos que já ocupavam os locais de implantação das colônias de imigrantes europeus antes do povoamento racionalista, contribuindo para a instituição de um ethos específico no local voltado para valores como "trabalho" (privado), "progresso" (moderno), "família" (patriarcal) e "religiosidade" (cristã).

Algumas questões de partida, ainda que aparentemente simples, podem auxiliar na elaboração sociológica da problemática. O discurso do pioneirismo configura uma elite? Caso positivo, que tipo de elite seria? Quais suas especificidades enquanto tal? Quais seus domínios? O que garante seu poder e sua proeminência?

Sugiro que o discurso do pioneirismo gera uma espécie de elite que se manifesta, também, em termos culturais. ${ }^{3}$ Para isso, apoio o princípio de realidade da problemática no contexto histórico e social da cidade de Toledo, localizada na região Oeste do Paraná. ${ }^{4}$ Indico como esse discurso permite uma identificação (OLIVEIRA, 1976) entre determinado contingente de pessoas, constituindo um princípio de identidade e reconhecimento. Vamos perceber no decorrer da argumentação como alguns aspectos sociais, arbitrados como excepcionalidades de determinado segmento social, são eleitos como constituintes de uma identidade social, um "Nós" em oposição a "Outros". Relação de alteridade que marca fronteiras entre grupos humanos, limites entre dentro e fora e, logo, um jogo de inclusões e exclusões.

\footnotetext{
3 Embora também mantenha relações com as esferas política e econômica, o presente texto circunscreve especificamente a esfera cultural onde se manifesta o discurso do pioneirismo.

${ }^{4}$ Para informações gerais sobre o município, assim como fotos: http://www.toledo.pr.gov.br
} 
Segundo Oliveira (1976, p. 5) “a apreensão dos mecanismos de identificação nos parece fundamental [...] porque eles refletem a identidade em processo. Como é assumida por indivíduos e grupos em diferentes situações concretas”. Essas identificações concebem concomitantemente relações sociais que geram laços e rupturas, pois engendram a lógica da "identidade contrastiva" que "parece se constituir na essência da identidade étnica, [...] implica a afirmação do nós diante dos outros. [...] É uma identidade que surge por oposição. Ela não se afirma isoladamente" (OLIVEIRA, 1976, p. 5).

Sejam elas étnicas, de gênero, geração, religiosas ou de classe (etc.) as identidades/identificações configuram instituições de relações sociais pautadas num ethos conjunto de valores, práticas, normas, usos e costumes sociais que tendem a definir as características de determinado contingente populacional. A estratégia que subjaz à instituição é, antes de tudo, diferenciar. Concomitantemente, sendo necessária para sua manutenção, a naturalização de tais diferenciações cria fronteiras simbólicas mais ou menos rígidas. Uma vez diferenciados, os grupos engendram entre si relações sociais de dominação e poder que não raro são estabelecidas com violência - especialmente nos casos em que o mito fundador da diferença não foi naturalizado pelos dominados. Segundo Bourdieu (2008, p. 101),

o ato de instituição é um ato de comunicação de uma espécie particular: ele notifica a alguém sua identidade, quer no sentido de que ele a exprime e a impõe perante todos [...], quer notificando-lhe assim com autoridade o que esse alguém é e o que deve ser.

A categoria discurso, como a utilizo aqui, não diz respeito apenas à língua falada, mas à linguagem em geral. A linguagem dá vazão aos desejos humanos. Participa da constituição do discurso, que também é contemplado por imagens, como no caso dos monumentos erigidos aos "pioneiros". O discurso caracteriza-se por ser o ponto de articulação entre os fenômenos linguísticos e os processos de representação, entre a linguagem, a enunciação e a prática.

A linguagem enquanto discurso não constitui um universo de signos que serve apenas como instrumento de comunicação ou suporte de pensamento; a linguagem enquanto discurso é interação, e um modo de produção social; ela não é neutra, inocente nem natural (BRAND ̃̃O, 2004, p. 11).

Segue uma breve contextualização sobre a trama do pioneirismo na cidade de Toledo, Paraná, por meio da qual desenvolvo algumas reflexões acerca da problemática desse discurso como fomentação de uma espécie de elitismo.

\section{Toledo: a origem da colônia e a colonização das origens}


Toledo é sugestivamente remissiva à "colonização" e "pioneirismo". Especialmente nos espaços públicos como o "Parque dos Pioneiros", a "Vila Pioneiro", o "Museu Municipal Willy Barth", 5 nos monumentos erigidos em homenagem às "famílias pioneiras", nas cores da bandeira (verde, vermelho e branco, remetendo à bandeira italiana), no brasão da cidade (onde constam dois machados, uma araucária e dois livros), no hino oficial do município intitulado "Toledo, cidade labor", na APITO (Associação dos Pioneiros de Toledo) e até mesmo no espaço preferencial que esses "civilizadores do inóspito" garantiram para si em frente à cruz principal do cemitério municipal central, onde apenas "pioneiros" podem ser sepultados. De acordo com Pinçon e Pinçon-Charlot (1999, p. 18) “o espaço urbano é, pois, ele também um espaço de relações onde os lugares, os bairros, os equipamentos dialogam, se respondem e se afrontam".

Há um arranjo discursivo montado no sentido de enaltecer, publicizar e propagar o imaginário ${ }^{6}$ de uma suposta odisseia dos "colonizadores pioneiros". Um exemplo é o "Memorial do Pioneiro". Inaugurado em 2010, esse monumento instigou as disputas geradas em torno de "quem é" e "quem não é" "pioneiro" do município. O monumento foi construído em frente à catedral mais antiga, maior e mais central da cidade, ostentando o nome completo dos considerados "pioneiros" em pomposas placas de bronze apregoadas em monólitos de concreto envelhecido, dispostos na ampla calçada formando uma fileira simétrica.

Numa das placas que constam os nomes dessas pessoas também se limita temporalmente a possibilidade de acesso à comunidade toledana pioneira: são considerados pioneiros apenas indivíduos chegados entre os anos de 1946 e 1952, ${ }^{7}$ respectivamente, início da "colonização" e ano de emancipação política do município. De acordo com Lângaro (2012, p. 16) "se tornou hegemônico o entendimento de que 'colonização' é sinônimo de história local e regional, na condição de enredo obrigatório - quando não, único - para se narrar o passado do lugar”.

Apesar de Toledo ser uma cidade etnicamente plural, ${ }^{8}$ onde convivem pessoas oriundas de "protocélulas" (RIBEIRO, 1995, p. 271) socioculturais diferenciadas, nem todos são contemplados nos espaços de reconhecimento público do local. Destacadamente aqueles cujas “origens" não figuram entre as mais "civilizadas" no interior das fronteiras da modernidade. São

\footnotetext{
${ }^{5}$ Foi o segundo diretor da MARIPÁ, madeireira responsável pela "colonização" de Toledo. Um dos promotores da expansão e da modernização de Toledo, também fundou uma cidade vizinha a Toledo, Marechal Cândido Rondon. Encontra-se sepultado no local reservado aos pioneiros no cemitério municipal de Toledo, ao lado de outras personalidades do pioneirismo, como o padre Antônio Patuí.

"Uso o termo "imaginário" como sinônimo de "representação", isto é, caracterizando um conjunto de esquemas de compreensão que podem ser atribuídos a determinados contingentes populacionais num dado espaço-tempo. Portanto, não no sentido comum de "fantasia".

${ }^{7}$ Esse foi o primeiro marco temporal do pioneirismo de acordo com o monumento, por sua vez, elaborado pelo Museu Municipal Willy Barth.

${ }^{8}$ Segundo dados censitários do IBGE 2010 (IPARDES, 2013, p. 10) a distribuição étnica, dita de "raça ou cor", no município de Toledo corresponde às seguintes proporções: "brancos(as)" 82.467; "pretos(as)" 3.474; "amarelos(as)" 1.029; "pardos(as)" 32.269 e "indígenas" 74, totalizando 119.313 pessoas. Para 2013 a população estimada foi de 128.448 pessoas. Em Toledo, há também a presença de descendentes de imigrantes de nacionalidade japonesa.
} 
os "índios", os "paraguaios", "negros", e/ou "nordestinos". A esses contingentes populacionais, assim estereotipados, a história que se quer oficial reserva uma parca participação na construção do "progresso local". Ainda que muitos tenham trabalhado intensamente seja no desmatamento, nas lavouras ou mesmo na indústria e no comércio locais, suas histórias pouco contracenam com a dos "colonizadores pioneiros", sendo invisibilizadas pelo discurso histórico hegemônico que predomina no local.

Atualmente, o território que abrange a mesorregião Oeste do Paraná compreende área de $15.000 \mathrm{~km} .{ }^{2}$ Já a cidade de Toledo reúne em torno de si uma microrregião que engloba 21 municípios. A cidade de Toledo originou-se a partir do encerramento das atividades de uma obrage denominada "Fazenda Britânia". O marco inicial de Toledo é atribuído ao ano da compra das terras da Fazenda pela empresa Industrial Madeireira Colonizadora Rio Paraná S.A. - ou simplesmente "Maripá" - em 1946.

O período entre 1946-1952 é amiúde tido como o tempo da "epopeia” dos “colonizadores pioneiros". Entretanto, sabe-se que, mesmo com a chegada dos "colonizadores rio-grandenses", um determinado contingente de população destoante do binômio ítalo-teuto permaneceu como remanescente do local. Embora não haja dados exatos relativos à quantidade de pessoas que permaneceram ali após o encerramento da obrage, pode se ter uma vaga ideia a partir dos nomes das pessoas sepultadas como indigentes no cemitério central, recentemente resgatados por iniciativa municipal, totalizando mais de 400 indivíduos. E esse é certamente um número modesto se considerarmos todo o universo dos que permaneceram, de seus descendentes, dos que foram baratinados e/ou que chegaram posteriormente à demarcação temporal do pioneirismo.

A intensificação do processo de "colonização" dessa região deu-se a partir do Estado Novo e do programa nacionalista "Marcha para o Oeste", promovido pelo governo de Getúlio Vargas como medida que garantiria a manutenção da soberania nacional sobre esse território de fronteiras que, no passado, havia sido motivo de acirradas disputas internacionais. Essa região foi ocupada por diversas empresas estrangeiras de extração de madeira e erva-mate, com a qual se alimentava boa parte do mercado platino formado por Argentina, Uruguai e Paraguai (WACHOWICZ, 1982). O propósito do governo nesse aspecto concentrava-se na conciliação entre fronteiras geopolíticas e econômicas, além de interesses oligárquicos da elite gaúcha ligada a Getúlio Vargas (GREGORY, 2002).

\footnotetext{
${ }^{9}$ Propriedade privada cuja atividade econômica se baseava na exploração natural típica das regiões cobertas pela mata subtropical em território argentino e paraguaio. Sua existência baseava-se no binômio mate-madeira. Os proprietários dessas empresas de exploração (natural e humana) são chamados "obrageros"; os trabalhadores, “mensus" (WACHOWICZ, 1982, p. 11).
} 
A concepção de "frente pioneira" é oriunda da geografia a partir da década de 1940, sob a ótica da sociedade nacional, isto é, dos não índios, pressupondo propriedade da terra. Já "frente de expansão", originária na antropologia da década de 1950, designava reverberações locais da expansão do capital sobre as florestas e os povos que nela habitavam, pressupondo posse da terra. Portanto, há uma diferença pontual entre ambas (MARTINS, 2009). A frente pioneira indica o novo, o movimento que suplanta a mata e torna as "terras devolutas" em propriedades produtivas. De acordo com Martins (2009, pp. 135-136),

a concepção de frente pioneira compreende implicitamente a ideia de que na fronteira se cria o novo, nova sociabilidade, fundada no mercado e na contratualidade das relações sociais. [...] A frente pioneira é também a situação espacial e social que convida ou induz à modernização, à formulação de novas concepções de vida, à mudança social.

O discurso promovido pelo governo do Estado Novo, em sintonia com as "empresas colonizadoras", motivou a migração de milhares de pessoas para as novas fronteiras agrícolas na década de 1940. A memória do bandeirantismo, por um lado, contribuiu como elemento fomentador ideológico-nacionalista. Por outra via, houve o discurso da etnicidade, da família, da “origem”, através do qual se permitia vislumbrar a expansão da sociabilidade típica dos “eurobrasileiros" (GREGORY, 2002), instalados no sul, para outras regiões. No caso de Toledo, e da região Oeste em geral, os nascentes povoados estabeleceram-se com um grau relativamente elevado de homogeneidade social e cultural que se manteve até o período de modernização, contribuindo para a eclosão de sentimentos comuns de etnicidade entre os "migrantes sulistas".

A categoria "etnia", embora controversa, ${ }^{10}$ serve de conceito operacional na tarefa de elaborar a peculiaridade dos pioneiros e pioneiras no caso de Toledo. É uma ferramenta adequada não porque exprime realmente alguma regionalidade peculiar e essencial dos grupos sociais, mas justamente porque se encontra, talvez escamoteada, nos fundamentos do discurso do pioneirismo em questão. Isso porque, para além da noção de "raça", muitas vezes implícita, ela também remete a outros valores compartilhados como próprios, como o local de nascimento, a religiosidade, ${ }^{11}$ a língua e o parentesco. ${ }^{12}$ De acordo com Poutignat e Streiff-Fenart (1998, p. 38), podemos considerar a etnicidade como um meio de identificação cultural que remonta às "origens comuns" de determinado contingente populacional, isto é, como

um tipo particular de grau social que se alimenta de características distintas e de oposições de estilos de vida, utilizadas para avaliar a honra e o prestígio segundo um sistema de divisões sociais verticais. Mas essas características distintivas só têm eficácia

\footnotetext{
${ }^{10}$ Para perspectivas e controvérsias em torno da categoria "etnia" cf. BAO, 2014. PP. 41-65.

${ }^{11}$ A religiosidade é um elemento muito presente em contextos de colonização como o de Toledo. Embora cristãs, as colônias rivalizavam entre católicos e protestantes. No presente texto não abordo essa questão. Para mais informações sobre esse aspecto, cf. OTTO (2006).

${ }^{12}$ Para uma perspectiva relacional da noção de "grupos étnicos”, cf. BARTH (1998).
} 
na formação dos grupos étnicos quando induzem a crer que existe, entre os grupos que existem, um parentesco ou uma estranheza de origem.

Durante o alvorecer da "colonização" da região em questão, imperava o ideal de se evitar certos grupos sociais no processo. Apoiar um projeto colonizador, baseado no modelo da ordem racional e do progresso econômico, em "tipos humanos inapropriados", era ao que não estavam dispostos capitalistas, estadistas e a opinião da população migrante em geral - ao menos a ligada ao binômio ítalo-teuto. Importante sublinhar que a grande maioria, nesse caso específico, eram provenientes do Rio Grande do Sul. Observando o quadro de acionistas da "empresa colonizadora" Maripá, percebemos que era composto por proprietários cujas "raízes étnicas" remetiam a descendentes de imigrantes italianos/as (33\%) e alemães/alemãs (66\%) (WACHOWICZ, 1982, p. 167). Nesse sentido, um primeiro problema associado à demanda étnica da "colonização" de Toledo era que

para a consecução dos planos de colonização, os trabalhadores remanescentes da região se constituíam em empecilho, pois os eurobrasileiros tinham restrições em participar da colonização de áreas onde havia presença de pessoas "sem origem". Desta forma, a questão étnica se confundia com interesses econômicos das empresas madeireiras e colonizadoras. (GREGORY, 2002, p. 93).

Temos, portanto - como o próprio Gregory (2002) subscreve com o termo "eurobrasileiros"13 - uma categoria étnica que atribui-se auto reconhecimento devido às suas origens ancestrais extra nacionais, ou seja, "europeias”, em oposição aos "outros”, identificados sob o termo genérico de "sem origem", em geral descendentes de povos originários/indígenas, mas também "paraguaios", "negros" e "nortistas" que circulavam pela região. Nos seus andaimes mais fundamentais, o discurso do pioneirismo sustenta-se em pressupostos étnicoraciais. Sugere que pessoas com uma ligação genética ${ }^{14}$ com indivíduos originariamente provenientes do que se conhece como "Europa" possuem alguma espécie de superioridade inata com relação aos "outros" - imaginam-se "brancos" aos olhos Ocidentais.

Segundo Love e Barickman (2006, p. 84), “as relações da elite com o estrangeiro são obviamente um aspecto importante - ainda que com frequência negligenciados nos estudos sobre as elites -, sobretudo em países economicamente dependentes". Aqui também entram "distinções e títulos estrangeiros", como é o caso da dupla-cidadania, ou mesmo "esquemas de imigração", que envolvem laços familiares e sentimentos de pertencimento, "origens comuns" (POUTIGNAT; STREIFF-FENART, 1998; WEBER, 1999; BARTH, 1998).

\footnotetext{
${ }^{13}$ Para uma análise crítica acerca da produção historiográfica da (e sobre a) região Oeste do Paraná cf. LÂNGARO (2012).

${ }^{14}$ Para um argumento biogenético sobre a ineficiência da categoria "raça" para a classificação dos diversos grupos humanos, cf. BARBUJANI (2007).
} 
O inconveniente da "falta da origem" foi sanado com a limitação da venda de lotes coloniais apenas a pessoas "com origem". A propaganda da "empresa colonizadora" era promovida por corretores, no "boca-a-boca" e, em alguns casos, panfletada em comunidades de imigrantes europeus/europeias nas "colônias agrícolas" do Sul. Pretendeu-se não chamar a atenção de pessoas cuja "falta de origens" supostamente colocaria em "risco" o sucesso do empreendimento "colonizador". ${ }^{15}$ Não seria exagero afirmar que, ao menos durante seu alvorecer, o processo de ocupação racional do local onde hoje está a cidade de Toledo foi permeado por certa conduta eugenista. ${ }^{16}$

Portanto, o acesso àquelas terras foi limitado quase que exclusivamente aos agentes considerados por seus pares como "de origem", ao contrário dos "outros" não desejáveis para o projeto de "colonização". Isso permite estabelecer, no marco espaço-temporal inicial da dita colonização, uma comunidade pioneira supostamente "pura", formada (quase) exclusivamente por "descendentes de europeus" até meados da década de 1960. Inventa-se, assim, uma narrativa asséptica, um mito (no sentido corrente do termo) sobre os "pioneiros" e, logo, uma localidade arbitrária e privilegiada. Nesse sentido, pode-se afirmar que configuram uma espécie de elite local no que tange ao critério de reputação (LOVE; BARICKMAN, 2006). Assim como o discurso regionalista, podemos afirmar, com Bourdieu (2008, p. 110), que o discurso localista

é um discurso performativo, que visa impor como legítima uma nova definição de fronteiras [...] as categorias "étnicas" ou "regionais", como, por exemplo, as categorias de parentesco, instituem uma realidade valendo-se do poder de revelação e de construção exercido pela objetivação do discurso.

Com a emancipação política do município (14 de dezembro de 1952) e sua consequente expansão demográfica, tornou-se difícil controlar os acessos de entrada na emergente cidade que aspirava por "progresso" e "desenvolvimento", especialmente após a chegada de indústrias como a SADIA (atualmente BRfoods) e a instalação da hidrelétrica São Francisco (hoje desativada) em meados da década de 1960. A partir desse momento, como dito, o local sofreu mudanças substanciais devido ao processo de modernização, tornando as antigas identificações étnicocomunitárias opacas e fazendo crer aos grupos dirigentes locais que a situação demandava uma reação conservadora, no sentido de criarem-se fronteiras de "pureza" e homogeneidade étnicoracial que limitariam os acessos de entrada na "comunidade toledana original" ou, como é preferível, "pioneira".

Existiram diferentes sujeitos sociais que atuaram em Toledo no sentido de instituir e fomentar essas versões no espaço público, desde a década de 1950. A partir da década

\footnotetext{
${ }^{15}$ Foi assim que os mensus e outros trabalhadores remanescentes na região, assim como algumas pessoas de etnias distintas do binômio ítalo-teuto, foram expulsos e/ou impedidas de adquirirem lotes de terras em Toledo. Para mais informações cf. GREGORY (2002).

${ }^{16}$ Para informações gerais acerca do eugenismo, especialmente no caso brasileiro, cf. MACIEL (1999).
} 
de 1980, quando esses movimentos indiscutivelmente se intensificaram, existia um motivo local muito importante para o desenvolvimento desses projetos, uma vez que a cidade havia recebido novas populações vindas principalmente da zona rural, em busca de trabalho na área urbana. (LÂNGARO, 2012, p. 21).

Historicamente, é a partir desse momento que passam a ser explicitamente manipuladas e disputadas as fronteiras simbólicas do município de Toledo, mantendo excluídos os sujeitos que continuam a compor no presente os "outros" da "comunidade pioneira" toledana supostamente edificada no passado.

\section{Pioneirismo, capital simbólico e elitismo étnico}

O discurso do pioneirismo não se apresenta explicitamente como um interesse autoevidente e coordenado de dominação. É vivido e sentido como algo natural, como uma verdade, calcada num passado histórico muito específico que o originou e sustenta. Por outro lado ocorre e impõem-se, isto sim, devido à predominância de um segmento social específico caracterizado, em suma, por relações de parentesco e configurado numa espécie de elite cultural com demarcações temporais/históricas.

A promoção e consagração desse discurso de dominação exige altos investimentos em capital simbólico, como maneira de angariar lucros simbólicos utilizados na realimentação do discurso do pioneirismo e em suas interfaces com a política e a economia. O capital simbólico, na perspectiva de Bourdieu, remete a questões de prestígio, notoriedade, reconhecimento.

Chamo de capital simbólico qualquer tipo de capital [...] percebido de acordo com as categorias de percepção, os princípios de visão e de divisão, os sistemas de classificação, os esquemas classificatórios, os esquemas cognitivos [...]. O capital simbólico é um capital com base cognitiva, apoiado sobre o conhecimento e o reconhecimento. (BOURDIEU, 1996, p. 149).

A tentativa de estabelecer um "pioneirismo" é homóloga a de instituir um ethos arbitrário, isto é, modelo referente, "ideal", "normal", consagrado de conduta social. Fixando-se um marco espaço-temporal inicial, precursor, pioneiro, estimula-se um modelo de comportamento desejável que, a partir de suas fundações colonialistas, se reproduza sobre as mesmas bases linearmente, ad infinitum. Esse discurso tende à invisibilização dos "outros" participantes do contexto social devido a seu léxico dicotômico que opõe "pioneiros" e "nãopioneiros" na narrativa histórica hegemônica sobre a origem do local. A sensação gerada por esse discurso é de que o "passado laborioso" dos "pioneiros" é o substrato fundamental do "progresso" da cidade e, devido a isso, deve-se reconhecer a primazia desse projeto - e dos 
agentes que o empreendem - sobre outros grupos sociais, práticas, culturas ou temporalidades. ${ }^{17}$ Essa espécie de elitismo cultural dá-se em termos simbólicos. Promove o estabelecimento de um modelo de relações sociais verticalizado, onde o lugar social preponderante cabe aos pioneiros/as. ${ }^{18}$

Essa elite cultural está delimitada como aqueles que se reconhecem e são reconhecidos como pioneiros de acordo com os marcos temporais estabelecidos pelos discursos históricos. Não se trata de um grupo homogêneo e absolutamente definido. Há várias intersecções possíveis no interior das fronteiras do pioneirismo em Toledo. Os próprios marcos temporais estão em disputa. Mas, oficialmente, de acordo com os discursos e os monumentos erigidos aos pioneiros a demarcação temporal é evidente e, mais importante, os elementos que compõe esse imaginário do "pioneiro colonizador" são apresentados como a "verdadeira cultura", representando os valores supostamente corretos que devem ser aceitos e incorporados como exemplares. Logo, um arranjo que proporciona dominação por meio da consagração de um arquétipo simbólico que tende a definir comportamentos de acordo com uma referência padrão, mas que diz respeito a um grupo específico que habita a cidade, em detrimento da heterogeneidade cultural do local, que figura como "cultura marginal".

A elite pioneira é um grupo dirigente na esfera cultural da cidade de Toledo, é o que garante seu elitismo. Sabemos que é assim porque há investimentos pesados na promoção desse discurso, seja por meio do Museu Willy Barth, da construção de monumentos públicos, do conteúdo da educação escolar básica, da mídia impressa ou da publicação de literaturas (científicas ou não) que reificam essa categoria altamente essencializada. Coradini (2003) bem demonstrou a posição decisiva dos intelectuais para a reificação dos ethos específicos subjacentes às noções de "política" e de "cultura" na conformação e nas reconversões de elites no Rio Grande do Sul. ${ }^{19}$ Em Toledo e na região Oeste como um todo não é diferente. Universidade e burocracia estatal participam ativamente na rede de acionistas investidores nesse capital simbólico.

A característica fundamental utilizada como elemento de distinção dos pioneiros em Toledo reside nos cortes temporais aplicados ao discurso do pioneirismo, onde o período entre 1946-1952 é o mais aceito, com algumas variações para mais em versões marginais, menos

\footnotetext{
${ }^{17}$ Não há na cidade monumentos que glorifiquem os mensus praticamente escravizados nas obrages da região antes da "colonização". Assim como também não há homenagens (salvo possíveis efemeridades) aos indígenas que ocuparam e ainda ocupam a região, ou mesmo aos descendentes de negros escravizados que compõem decisivamente a configuração da nação brasileira. A figura absolutamente predominante é a do colonizador pioneiro.

${ }_{18}$ Assim como em Toledo, a invisibilização de indígenas e negros e a exaltação da descendência europeia predomina em boa parte do Brasil. Além da região Sul, em Mato Grosso do Sul, Mato Grosso, São Paulo, entre inúmeras partes do Brasil, os mesmos fenômenos são recorrentes.

${ }^{19}$ Esse parece ser o caso de investimentos do poder público municipal em atividades como o "Projeto história" que culminou, em 1988, na compilação do livro "Toledo e sua história", escrito por Oscar Silva, Rubens Bragagnollo e Clori Fernandes Maciel. Há ainda uma série de obras literárias locais que abordam questões relacionadas. Para isso, cf. Beal (2009), Costa (2002), Niederauer (2004), Grondin (2007). Para mais informações cf. LÂNGARO (2012).
} 
dotadas de investimentos em capital simbólico. Evidente que a hegemonização de um determinado discurso, seguido de um ethos particular, carece de ritos de instituição e consagração. A questão é, igualmente, qual a lógica do argumento mobilizado no discurso? No caso presente, ocorre um corte temporal arbitrário, consagrando um segmento social que se compreendia desde o início como ocupando as mais altas posições na hierarquia das civilizações, acreditando, com veemência, que tais verticalidades são verdadeiras, que consistem em causas naturais.

É notável o fato de que sua distinção não pode basear-se no argumento de ter "chegado antes", como indica o significado etimológico do termo "pioneiro". ${ }^{20}$ Primeiro por que ali já havia há tempos, e continua havendo, grupos indígenas, ${ }^{21}$ depois porque muitos remanescentes da Fazenda Britânia ali permaneceram. O que os distingue também não pode ser, como querem muitos, a vanguarda do "progresso" local. Isso não teria ocorrido sem a intensa participação de trabalhadores provenientes de outras origens socioculturais, ou étnicas, desde o início, desde a derrubada das matas até a modernização, com o emprego de força de trabalho assalariada em geral. Portanto, o que consagra a "elite pioneira" como tal, qual seu elemento fulcral de distinção?

Limitado aos anos iniciais do povoamento, o período da "epopeia pioneira" consagra apenas sujeitos pertencentes aos grupos que eram aceitos como compradores e moradores no local, isto é, descendentes de imigrantes das colônias do Sul. Eram majoritariamente proprietários de terras - muitos agricultores -, comerciantes, profissionais liberais e seus familiares. Em suma "brancos", "heterossexuais", “cristãos”, “capitalistas".

O fundamento que sustenta os andaimes do discurso do pioneirismo, por conseguinte, só pode ser o das "origens comuns", da etnia e, veladamente, da "raça". Não porque apenas "descendentes de europeus" podem ser pioneiros, ou mesmo que apenas esses caibam nos estereótipos apresentados no final do parágrafo anterior; mas porque apenas esses eram aceitos como iguais, isto é, reconhecidos na então emergente comunidade local durante o período que compreende o tempo do pioneirismo (1946-1952). Assim, o discurso do pioneirismo estabelece um corte, uma distinção que se dá aparentemente apenas em termos temporais, mas que, sob essa aparente coerência, reproduz uma segregação sociocultural bem mais ampla e presente do que sugere sua nostálgica narrativa.

Enquanto o discurso étnico pode ser mais facilmente evidenciado, o da "raça" fica escamoteado, pois representa uma profanação moral no atual contexto multicultural. Segundo

\footnotetext{
${ }^{20}$ O termo "pioneiro", segundo Cunha (2007, p. 606) significa “explorador (de sertões)" e/ou "precursor", tendo sua origem na palavra francesa pionnier, como era conhecido o soldado que se deslocava a pé e chegava antes da tropa, podendo com isso obter informações sobre o caminho.

${ }^{21}$ Cf. SANTOS (1998) e RIBEIRO (1995).
} 
Bourdieu (2008, p. 100), “as distinções socialmente mais eficazes são aquelas que parecem se fundar em diferenças objetivas" como sexo/gênero, cor da pele, idade, aspectos físicos (etc.). A distinção étnica, da origem cultural e do fenótipo atuam como naturais, são praticamente auto evidentes. A própria noção de "etnia" acaba por reiterar o imaginário da "raça" (BOURDIEU, 2008, p. 107).

Os pioneiros constituem uma espécie de elite cultural porque dominam a narrativa histórica e cultural em Toledo. Detém um poder que não está oculto na suposta essência de sua etnia, nem sob os textos, imagens e monumentos edificados à "glória dos pioneiros", mas que emana do que as representações desse discurso "criam em sua exterioridade e da própria diferença com que descrevem” (ALBUQUERQUE JÚNIOR, 1999, p. 24) - ação social que tende a contribuir para a reprodução de famílias ligadas ao pioneirismo também em outras esferas.

O investimento no discurso do pioneirismo caracteriza um recurso empregado na reprodução sociocultural de grupos cuja herança cultural contribui para garanti-los um lugar social privilegiado, proeminente. Sua legitimidade é fruto da luta pela consagração de determinadas representações como "naturais", isto é, de um ethos. Há interesses por trás da vontade de fazer-se pioneiro/a. Os portadores e porta-vozes do grupo, agindo aqui e ali, por meio de uma "alquimia da representação" (BOURDIEU, 2008, p. 82-83), contribuem para a consagração de uma narrativa histórica e moral arbitrária que, uma vez instituída, logicamente os alçam às posições simbólicas dominantes no local.

O caso de Toledo, nessa perspectiva, indica como a narrativa histórica de um local, quando cooptada por um grupo dominante, tende a produzir consenso sócio histórico arbitrário, onde as memórias são apropriadas e reconfiguradas por estes agentes que pretendem garantir para a elite que representam a hegemonia sociocultural naquele local. Representa os perigos inerentes a uma história única, unilateral.

\footnotetext{
Quando um grupo trabalha intensamente em conjunto, há uma tendência de criar esquemas coerentes de narração e de interpretação dos fatos, verdadeiros "universos de discurso", "universos de significado", que dão ao material de base uma forma histórica própria, uma versão consagrada dos acontecimentos. O ponto de vista do grupo constrói e procura fixar a sua imagem para a História. (BOSI, 1987, p. 27).
}

Nesse sentido, é possível perceber “as memórias da 'colonização' em Toledo não como recordações fortuitas do passado local, mas como partes de um processo político de construção de domínios na cidade, relações de poder e hegemonia" (LÂNGARO, 2012, p. 27) entre os diversos grupos que compõem o mosaico sociocultural do local.

\section{Considerações finais}


O mito do "colonizador pioneiro" não raro revela-se sórdido, na medida em que procura garantir para si a hegemonia temporal sobre determinados locais; assim como se arroga progressista negando o lado obscuro do "progresso", sempre acompanhado por batalhões de miseráveis relegados às bordas externas do sistema social. O discurso que gera e sustenta a "elite pioneira", calcado numa série de ritos de consagração, estimula a perpetuação de supostas diferenças socioculturais e reverbera, no presente, aspectos discriminatórios ligados a preconceitos étnico-raciais históricos que são, amiúde, considerados como superados pela "civilização moderna".

Assistimos ao desdobramento de relações seculares de dominação que contribuem em manter uma estrutura social verticalizada, dominada por elites, mesmo no interior de um sistema político e social deliberadamente democrático. Nesse sentido, o presente texto almeja contribuir para a explicitação dos equívocos associados ao discurso da meritocracia - que supostamente garante a todos/as uma igualdade de partida no acesso às posições sociais de maior prestígio e rendimentos financeiros - indicando como há engrenagens ocultas que interferem de modo arbitrário, personalista e desigual no arranjo e na manutenção do sistema social. Ora, os ditos pioneiros de Toledo e, logo, seus descendentes, evidentemente obtém privilégios com esse discurso.

Por outro lado, seria no mínimo ingenuidade supor que haja horizontalidade no interior do grupo dos "pioneiros". Aí também existem as disputas por posições de destaque entre os subgrupos - em suma familiares - que compõem o contingente populacional da elite pioneira. Entre outras passagens, isso fica nítido na luta existente pela temporalidade do pioneirismo, pela sua delimitação cronológica, evidenciada pelas alterações feitas desde o início nas placas do "Monumento ao Pioneiro". Nesse sentido, Bourdieu (1996a, p. 301) afirma que "as diferenças de posição no seio do grupo [...] retraduzem-se em uma participação desigual nos lucros do capital simbólico acumulado".

Há um campo de estudo relativamente pouco explorado no que tange à problemática aqui exposta, sobretudo com respeito a pesquisas levadas a cabo em outras regiões onde haja "elites pioneiras", assim como a relação desse imaginário cultural com as esferas social e política. Seria interessante a consecução de estudos comparativos entre os contextos históricos e os discursos correlatos do pioneirismo para a confecção de uma grade comparativa de características. 


\section{Referências}

ALBUQUERQUE JÚNIOR, Durval Muniz de. A invenção do Nordeste e outras artes. São Paulo: Cortes. 1999.

BAO, Carlos Eduardo. Fronteiras da "italianidade": representações entre gerações na cidade de Toledo/PR (1990-2014). Dissertação em Sociologia Política. Florianópolis: UFSC/PPGSP.

2014.

BARBUJANI, Guido. A invenção das raças. São Paulo: Contexto. 2007.

BARTH, Fredrick. "Grupos étnicos e Suas Fronteiras". In: POUTIGNAT, Philipp.e STREIFF-FENART, Joceline. Teorias da Etnicidade. São Paulo: UNESP. 1998.

BEAL, Vitor. Tempo de heróis: a parte esquecida da história de Toledo, que o tempo não conseguiu apagar. Toledo: FGM Gráfica e editora. 2009.

BOSI, Ecléa. Memória e sociedade: lembranças de velhos. $2^{\circ}$ ed. São Paulo: Editora da Universidade de São Paulo. 1987.

BOURDIEU, Pierre. "Introdução a uma sociologia reflexiva". In: BOURDIEU, Pierre. O poder simbólico. Rio de Janeiro: Bertrand Brasil. 1989.

As Regras Da Arte: gênese e estrutura do campo literário. São Paulo: Companhia das letras.1996a.

“É possível um ato desinteressado?”. In: BOURDIEU, Pierre. Razões práticas: sobre a teoria da ação. Campinas: Papirus. 1996b.

A economia das trocas linguísticas: o que falar quer dizer. $2^{\circ}$ ed. São Paulo: Editora da Universidade de São Paulo. 2008.

BRANDÃO, Helena Hathsue Nagamine. Introdução à análise do discurso. $2^{\circ}$ ed. Campinas: Editora da Unicamp. 2004.

CORADINI, Odaci Luiz. "As missões da "cultura" e da "política": confrontos e reconversões de elites culturais e políticas no Rio Grande do Sul (1920-1960)". Estudos Históricos, $\mathrm{n}^{\circ}$ 32. pp. 125-144. 2003.

COSTA, Luiz Alberto Martins da (Coord.). Toledo 50 anos - Cinco décadas de histórias. Toledo: Sul Gráfica. 2002.

(coord.). Calendário histórico de Toledo: cronologia de fatos, registros e curiosidades da história do município de Toledo. Toledo: GFM Gráfica e editora. 2009.

CUNHA, Antônio Geraldo da. Dicionário etimológico da língua portuguesa. Rio de Janeiro: Lexikon Editora Digital. 2007. 
GIDDENS, Anthony. A constituição da sociedade. $2^{\circ}$ ed. São Paulo: Martins Fontes. 2003.

GREGORY, Valdir. Os Eurobrasileiros e o Espaço Colonial: Migrações no Oeste do Paraná. Cascavel: Edunioeste. 2002.

GRONDIN, Marcelo. O alvorecer de Toledo: na colonização do Oeste do Paraná. Marechal Cândido Rondon: Ed. Germânica. 2007.

IPARDES, Instituto Paranaense de Desenvolvimento Econômico e Social. Caderno estatístico do município de Toledo [online]. Disponível em: http://www.ipardes.gov.br/cadernos/Montapdf.php?Municipio=85900. Acessado em 0409-2013 às 17:01 hs. 2013.

LÂNGARO, Jiani Fernando. Quando o futuro é inscrito no passado: "colonização" $e$ "pioneirismo" nas memórias públicas de Toledo-PR (1950-2010). Tese em História. São Paulo: PUC-SP. 2012.

LOVE, Joseph L.; BARICKMAN, Bert J. "Elites regionais". In: HEINZ, Flávio M. (Org.). Por outra história das elites. Rio de Janeiro: Editora FGV. 2006.

MACIEL, Maria Eunice de S. “A eugenia no Brasil". Revista Anos 90, n 11. pp. 121143. 1999.

MARTINS, José de Souza. Fronteira: a degradação do Outro nos confins do humano. São Paulo: Contexto. 2009.

NIEDERAUER, Ondy Hélio. Toledo no Paraná: a história de um latifúndio improdutivo, sua reforma agrária, sua colonização, seu progresso. $2^{\circ}$ ed. Toledo: Tolegraf impressos gráficos Ltda. 2004.

OLIVEIRA, Roberto Cardoso de. Identidade, etnia e estrutura social. São Paulo, SP: Pioneira. 1976.

OTTO, Claricia. Catolicidades e italianidades: tramas do poder em Santa Catarina (1875-1930). Florianópolis: Insular. 2006.

PINÇON, Michel; PINÇON-CHARLOT, Monique. "A teoria de Pierre Bourdieu aplicada às pesquisas sobre a grande burguesia: uma abordagem plural para uma metodologia pluridisciplinar”. Revista de Ciência Humanas, n² 25. pp. 11-20. 1999.

POUTIGNAT, Philippe; STREIFF-FENART, Jocelyne. Teorias da Etnicidade seguido de grupos étnicos e suas fronteiras de Fredrik Barth. São Paulo: Fundação Editora da UNESP. 1998.

RIBEIRO, Darcy. O povo brasileiro: a formação e o sentido do Brasil. $2^{\circ}$ ed. São Paulo: Companhia das Letras. 1995. 
SANTOS, Sílvio Coelho dos. "Os índios Xokleng e os imigrantes". In: FLEURI, Reinaldo Matias (Org.). Intercultura e movimentos sociais. Florianópolis: Mover, NUP. 1998.

SEIDL, Ernesto. "Estudar os poderosos: a sociologia do poder e das elites.". In: SEIDL, Ernesto; GRILL, Igor Gaspar (Orgs). As ciências sociais e os espaços da política no Brasil. Rio de Janeiro: FGV Editora. 2013.

SILVA, Oscar; BRAGAGNOLlO, Rubens; MACIEL, Clori Fernandes. Toledo e sua história. Toledo: Prefeitura Municipal de Toledo. 1988.

SÍTIO ELETRÔNICO DO MUNICÍPIO DE TOLEDO-PR [online]. Disponível em: http://www.toledo.pr.gov.br. Acessado em 12-10-2012 às 23:32 hs. [s.d].

WACHOWICZ, Ruy Christovam. Obrageros, Mensus e Colonos: história do Oeste paranaense. Curitiba: Ed. Vicentina. 1982.

WEBER, Max. Economia e sociedade: fundamentos da sociologia compreensiva. Vol. 1. $4^{\circ}$ ed. Brasília: Editora Universidade de Brasília. 1999. 